\title{
Evaluation and Correlation of Clinicopathological Parameters of Oral Squamous Cell Carcinoma of Gingivobuccal Sulcus with Lymph Node Status - A Retrospective Institutional Analysis in Navi Mumbai
}

\author{
Akash Shegaonkar1, Shilpa Patel², Niharika Swain, Jigna Pathak, Rashmi Hosalkar5, Rutuj Waghmare ${ }^{6}$ \\ 1, 2, 3,4,5, Department of Oral \& Maxillofacial Pathology, MGM Dental College \& Hospital, \\ MGMIHS, Navi Mumbai, Maharashtra, India. ${ }^{6}$ Department of Community Medicine, JNMC, \\ Datta Meghe Institute of Medical Sciences, Sawangi (M) Wardha, Maharashtra, India.
}

\section{ABSTRACT}

\section{BACKGROUND}

Mortality and Morbidity rates in the patients diagnosed with oral cancers remain static despite availability of advanced diagnostic and treatment modalities. For improving the survival status of the patients, a thorough understanding of the factors that predicts the progression of oral cancer is necessary to determine appropriate line of treatment. To do so in practise, critical knowledge regarding the prognostic factors that has high sensitivity holds immense importance. For determination of prognosis in oral cancer patients, clinical and histopathological parameters are widely used for assessment of treatment strategies. The primary objective of this study was to determine the clinical and histopathological prognostic factors in patients of oral squamous cell carcinoma of gingivobuccal sulcus (GBSSCC) treated by surgical intervention (neck dissection).

\section{METHODS}

Histopathological evaluation of archived samples of 60 GBSSCC patients which were treated by surgical intervention (Neck Dissection) in the time period from January 2011 to December 2020. Recurrent cases were excluded. Clinicopathological parameters such as age, sex, habit, tumour site, tumour size, tumour differentiation, depth of invasion, bone invasion, muscle invasion, perineural invasion \& extracapsular spread were evaluated \& then correlated with lymphnode status.

\section{RESULTS}

Among all the parameters, variables like habit (tobacco use) $(\mathrm{P}=0.045)$, tumour size $(P=0.003)$, perineural invasion $(P=0.000)$ emerged as independent prognosticators and significantly correlated to the lymph node status of the patients.

\section{CONCLUSIONS}

This analysis suggests that habit, tumour size, perineural invasion to be consistent, easy to assess and reliable independent prognosticators which are significantly correlated to the lymph node status. To conclude, it is of paramount importance to include the aforementioned prognosticators in histopathological reports for the prediction of clinical outcome and archiving of valued data for future analysis.

\section{KEY WORDS}

Oral Squamous Cell Carcinoma, Gingivobuccal sulcus, Lymph Node Status, ClinicoPathological Prognosticators
Corresponding Author: Dr. Niharika Swain, Associate Professor, Dept. of Oral \& Maxillofacial Pathology, MGM Dental College \& Hospital, MGMIHS, Navi Mumbai, Maharashtra, India. E-mail: niharikadec30@gmail.com

\section{DOI: $10.14260 /$ jemds/2021/469}

How to Cite This Article:

Shegaonkar A, Patel S, Swain N, et al. Evaluation and correlation of clinicopathological parameters of oral squamous cell carcinoma of gingivobuccal sulcus with lymph node status - a retrospective institutional analysis in Navi Mumbai. J Evolution Med Dent Sci 2021;10(30):22942299, DOI: 10.14260/jemds/2021/469

Submission 06-05-2021, Peer Review 05-07-2021, Acceptance 12-07-2021, Published 26-07-2021.

Copyright (C) 2021 Akash Shegaonkar et al. This is an open access article distributed under Creative Commons Attribution License [Attribution 4.0 International (CC BY 4.0)] 


\section{BACKGROUND}

Oral squamous cell carcinoma (OSCC) is the most common oral malignant neoplasm, constituting up to $80-90 \%$ of all malignant neoplasias of the oral cavity. ${ }^{1}$ The incidence of oral cancer is highly variable globally. It is generally established that oral cavity is one of the prominent anatomical locations for squamous cell carcinoma which also depends significantly on the geographic location (even specifically, regions in some countries) and demographic criteria of the individuals. ${ }^{1}$ Inspite of its mean incidence, it represents the most common location for cancer in some specific regions, especially in southeast Asia. ${ }^{1}$

Clinical site of placement of the tobacco quid may differ according to different tobacco habits and products. The various sites of placement of tobacco include lingual sulcus, maxillary gingivobuccal sulcus and the mandibular gingivobuccal sulcus. The chemical and mechanical irritants of the tobacco plays an important role in oral carcinogenesis.

The gingivobuccal sulcus complex usually consists of buccal mucosa, gingivobuccal sulcus, gingiva and retro molar trigone. In Indian subcontinent, mandibular gingivo-buccal sulcus (GBS) is the most common site affected by oral squamous cell carcinoma (OSCC) and hence, it is called as Indian Oral Cancer. ${ }^{2}$ An early gingivobuccal sulcus complex squamous cell carcinoma (GBSSCC) is often asymptomatic with most cases being usually identified in advanced stages sometimes involving nearby local regions and lymph node (LN) involvement. It comprises of total $40 \%$ of all OSCC with survival rate of $63 \%$ and $53 \%$ for 2 yr and $5 \mathrm{yr}$ respectively. Similarly the 5-yr survival rate in GBSSCC patients with lymph node metastasis (20 - 36\%) is comparatively less than those with no metastasis ( $63-86 \%)$. $^{3}$

Mortality and morbidity rates in the patients diagnosed with oral cancers remain static despite the availability of advanced diagnostic and treatment modalities. Inspite of the easy accessibility of the oral cavity for examination, OSCC is rarely diagnosed at initial stages. For improving the survival status of the patients, a thorough understanding of the factors that predict the progression of oral cancer is necessary to determine appropriate line of treatment. To do so in practise, critical knowledge regarding the prognostic factors that has high sensitivity holds immense importance. For determination of prognosis in oral cancer patients, clinical and histopathological parameters are widely used for assessment of treatment strategies. Lymph node (LN) metastasis is one of the most accepted and reliable prognostic markers for overall prognosis of cancer patients. The metastasis within the lymph node may be dependent, in turn, on various clinicopathological factors such as age, gender, site, treatment, habit, staging, etc., which help in determining the survival outcome of the patient.

Till now, various studies have been conducted to analyze the prognostic ability of various clinical and pathological factors associated with oral squamous cell carcinoma affecting different oral sub-sites. Hence the primary objective of this study was to evaluate and correlate the role of various clinicopathological factors with LN status with or without metastasis in GBSSCC patients.

\section{METHODS}

The present study is an institutional retrospective observational study. 78 patients were surgically intervened for SCC from January 2011 to December 2020. All the demographic details were retrieved for these 78 patients. After meeting the inclusion (Neck dissection cases only) and exclusion criteria (systemic diseases, recurrent cases and metastatic lesions) 60 cases of surgically operated for GBSSCC were selected for this retrospective study based on convenient sampling. Histopathological slides were retrived for reanalysis. Clinicopathological parameters like age, gender, site, habit, clinical staging, tumour differentiation, bone invasion, skeletal muscle invasion, perineural invasion and extracapsular involvement were noted. Evaluation and correlation of the factors with lymph node status were statistically assessed. Two independent pathologists reviewed the data and any discrepancy was solved by mutual consensus. Age of the patients was categorised into two groups i.e. $\leq 40$ and $>40$ yrs. Habits were categorised into 3 groups i.e. Smokeless, Smoke form and both. Clinical tumour size (cT) staging was given as per the AJCC 7th edition mainly. Tumour differentiation was graded by broders system (1927) for ease of analysis. Presence or absence of invasion in bone, muscle, and nerve was also assessed. Histopathological lymph node status was classified as positive or negative with or without extracapsular spread. This study protocol was approved by the institutional research review board. As the study is a retrospective observational one, the ethical approval for the same was not applicable. Though, the individuals informed consent for the surgery and use of the specimen for research purpose were acquired.

\section{Statistical Analysis}

Microsoft word and Excel were used to store the data and to generate graphs and tables. The descriptive and inferential statistical analyses were performed by using SPSS software version 21 (IBM, Armonk, NY, USA). Analysis of data with continuous measurements were presented as Mean SD whereas data with categorical measurements were depicted in numbers (\%). The level of significance was fixed at $\mathrm{P}=0.05$ and any value less than or equal to 0.05 was considered to be statistically significant. Chi-square analysis and Multivariate logistic regression analysis were run to find the significance of study parameters on a categorical scale.

\section{RESULTS}

Descriptive analysis of patient data showed that maximum study participants had a history of tobacco consumption in the form of smokeless tobacco (76.66\%) whereas only (16.66\%) used tobacco in smoke form. Out of 60 study samples, $68.33 \%$ were moderate tumour differentiation types followed by well and poor differentiation types $15 \%$ and $16.66 \%$ respectively. $61.66 \%$ of study samples did not show any evidence of bony, muscle or perineural invasions or extracapsular spread in metastatic lymph node. Only (38.33\%) of cases showed positive evidence of histopathological lymph node status. (Table 1). 


\begin{tabular}{|c|c|c|c|}
\hline Variables & Sub - Groups & $\mathbf{N}$ & $\%$ \\
\hline \multirow{2}{*}{ Gender } & Male & 40 & 66.66 \\
\hline & Female & 20 & 33.33 \\
\hline \multirow{2}{*}{ Age } & $\leq 40$ years & 13 & 21.66 \\
\hline & $>40$ years & 47 & 78.33 \\
\hline \multirow{3}{*}{ Habits } & Smokeless & 46 & 76.66 \\
\hline & Smoke form & 10 & 16.66 \\
\hline & Both & 4 & 6.66 \\
\hline \multirow{3}{*}{ Tumour Differentiation } & Well & 9 & 15 \\
\hline & Moderate & 41 & 68.33 \\
\hline & Poor & 10 & 16.66 \\
\hline \multirow{4}{*}{ Tumour Size } & T1 & 4 & 6.66 \\
\hline & T2 & 24 & 40 \\
\hline & T3 & 10 & 16.66 \\
\hline & $\mathrm{T} 4$ & 22 & 36.66 \\
\hline \multirow{2}{*}{ Bone Invasion } & Evident & 23 & 38.33 \\
\hline & Not evident & 37 & 61.66 \\
\hline \multirow{2}{*}{ Muscle Invasion } & Evident & 20 & 33.33 \\
\hline & Not evident & 40 & 66.66 \\
\hline \multirow{2}{*}{ Perineural Invasion } & Evident & 9 & 15 \\
\hline & Not evident & 51 & 85 \\
\hline \multirow{2}{*}{$\begin{array}{l}\text { Histopathological Lymph Node } \\
\text { Status }\end{array}$} & Positive & 23 & 38.33 \\
\hline & Negative & 37 & 61.56 \\
\hline \multirow{2}{*}{ Extra capsular Spread } & Evident & 23 & 38.33 \\
\hline & Not evident & 37 & 61.66 \\
\hline Table 1. Dis & ution of Stu & ble & \\
\hline
\end{tabular}

On comparison of lymph node status with other clinicopathological parameters, positive association was found in relation with different forms of habits. Within all metastatic lymph node cases, smokeless habit was found to be associated with lymph node metastasis as compared to other forms of tobacco habits. But when forms of habit were compared with positive and negative lymph node status, again smokeless form was found to be the most prevalent form of habit. In case of tumor size, the association with lymph node status could not be ascertained due to varied distribution of number of samples although the association was found to be statistically significant. On comparison with tumor differentiation, moderate and poor tumor differentiation cases showed higher instances of lymph node metastasis as compared to cases showing well tumor differentiation. Perineural invasion showed no association with occurrence of lymph node metastasis. (Table - 2).

\begin{tabular}{|c|c|c|c|c|c|}
\hline \multirow{2}{*}{\multicolumn{2}{|c|}{ Variables }} & \multicolumn{2}{|c|}{$\begin{array}{l}\text { Histopathological Lymph } \\
\text { Node Status }\end{array}$} & \multirow{2}{*}{$\begin{array}{c}\chi^{2}- \\
\text { Value }\end{array}$} & \multirow{2}{*}{$\begin{array}{c}P \text { - } \\
\text { Value }\end{array}$} \\
\hline & & $\begin{array}{l}\text { Positive } \\
(\mathrm{N}=23)\end{array}$ & $\begin{array}{l}\text { Negative } \\
(\mathrm{N}=37)\end{array}$ & & \\
\hline \multirow{3}{*}{ Habit } & Smokeless & 16 & 30 & \multirow{3}{*}{1.051} & \multirow{3}{*}{$0.043^{*}$} \\
\hline & Smoking & 05 & 05 & & \\
\hline & Both & 02 & 02 & & \\
\hline \multirow{4}{*}{ Tumour Size } & $\mathrm{T} 1$ & 00 & 04 & \multirow{4}{*}{4.198} & \multirow{4}{*}{$0.041^{*}$} \\
\hline & T2 & 12 & 12 & & \\
\hline & T3 & 03 & 07 & & \\
\hline & $\mathrm{T} 4$ & 08 & 14 & & \\
\hline \multirow{3}{*}{$\begin{array}{c}\text { Tumour } \\
\text { Differentiation }\end{array}$} & Well & 01 & 08 & \multirow{3}{*}{7.116} & \multirow{3}{*}{$0.004 *$} \\
\hline & Moderate & 15 & 26 & & \\
\hline & Poor & 07 & 03 & & \\
\hline \multirow{2}{*}{$\begin{array}{l}\text { Perineural } \\
\text { Invasion }\end{array}$} & Evident & 09 & 10 & \multirow{2}{*}{5.960} & \multirow{2}{*}{$0.043^{*}$} \\
\hline & Not evident & 14 & 27 & & \\
\hline \multirow{2}{*}{\begin{tabular}{|c|} 
Extracapsular \\
Spread
\end{tabular}} & Evident & 09 & 01 & \multirow{2}{*}{13.551} & \multirow{2}{*}{$0.000^{*}$} \\
\hline & Not evident & 14 & 36 & & \\
\hline \multicolumn{6}{|c|}{$\begin{array}{c}\text { Table 2. Comparison of Histopathological Lymph Node Status with } \\
\text { Different Variables Using the Chi-Square Test. (Variables Which } \\
\text { Showed Significant Correlation Are Only Included) }\end{array}$} \\
\hline
\end{tabular}

To check the independency of the prognostic factors, we performed a multivariate logistic regression analysis of the obtained data. As a result, we found that prognosticators such as habit, tumour size, perineural invasion were independent and were significantly correlated to the lymph node status of the patient.

\begin{tabular}{|c|c|c|c|c|}
\hline \multirow[b]{2}{*}{ Effect } & \multirow{2}{*}{$\begin{array}{l}\text { Model Fitting Criteria } \\
\text { - } 2 \text { Log Likelihood of } \\
\text { Reduced Model }\end{array}$} & \multicolumn{3}{|c|}{ Likelihood Ratio Tests } \\
\hline & & Chi - Square & df & Sig. \\
\hline Age & 46.308 & .003 & 1 & 0.959 \\
\hline Gender & 46.657 & .351 & 1 & 0.863 \\
\hline Habit & 11.620 & 1.032 & 2 & 0.045 \\
\hline Tumour Size & 54.874 & 8.569 & 3 & 0.003 \\
\hline $\begin{array}{c}\text { Tumour } \\
\text { Differentiation }\end{array}$ & 46.320 & .014 & 1 & 0.905 \\
\hline Bone Invasion & 46.558 & .252 & 1 & 0.615 \\
\hline Muscle Invasion & 46.595 & .289 & 1 & 0.591 \\
\hline Perineural Invasion & 62.117 & 15.812 & 1 & 0.000 \\
\hline Extracapsular Spread & 46.659 & .354 & 1 & 0.552 \\
\hline Intercept & 46.326 & .020 & 1 & 0.887 \\
\hline
\end{tabular}

\section{DISCUSSION}

Oral potentially malignant lesions and frank carcinoma occurs as a result of highly irritating mixtures of tobacco and slaked lime, which are widely used in Indian subcontinent. The major subsite for OSCC in India is gingivo-buccal sulcus because of placing / chewing habits of various tobacco forms. ${ }^{4,5}$ The recurrence and survival rate depends on various clinicopathological parameters such as age, gender, habits, site, tumour size, differentiation, bone invasion, muscle invasion, perineural invasion, extracapsular spread and lymph node status.

The present study has included cases that have undergone neck dissection for GBSSCC $(\mathrm{N}=60)$ out of which $\mathrm{N}=23$ have shown positive lymph node involvement and $\mathrm{N}=37$ have shown negative lymph node status. Lymph node metastasis is an established prognosticator of OSCC. But, the role of other clinicopathological factors in the prognosis of the tumours is yet to be determined. Thus, in our study we tried to evaluate and correlate clinicopathological factors with LN metastasis \& to understand their role in prognosis. We compared the clinicopathological prognostic factors with the lymph node status by using chi square test.

In our study most patients were above 40 yrs. of age i.e. approximately $78 \%$ of total patients which proved that age is an established risk factor for the cancers mainly because of accumulation of mutational changes throughout the life years and diminishing immune system. $67 \%$ of the patients were males and the rest were females which showed the predilection of cancers in males. Poor socio-economic status, easy acceptance of habits and labour associated tobacco consumption are attributed for male predilection. Habits and tumour site can be directly correlated in our study as $77 \%$ patients had a habit of smokeless tobacco chewing and all had common site to place it i.e. mandibular gingivo-buccal sulcus hence included in the study.

Among the total patients, the clinical tumour size ranged from $\mathrm{T} 2$ to $\mathrm{T} 4$ out of which $\mathrm{T} 2$ had the predominance suggesting that neck dissection was necessary despite the small clinical size of tumour thus improving prognosis of the patients. In this study, Broders system was used to grade the tumours and as a result moderate differentiation was found in $68 \%$ of cases. In correlation with the lymph node status it was not statistically significant but there was positive inclination from well to poor differentiation. Fang et al. Rikardsen et al. Choi et al. observed that cell differentiation was the most significant factor for lymph node metastasis, affecting prognosis and survival of OSCC. $6,7,8$ 
In OSCC, two different types of bone invasion is seen in mandible. In one type, saucerization of cortical bone occurs via osteoclastic resorption. In the other, bone marrow is infiltrated by tumour cells through the periodontal space or enlarged Volkmann and Haversian canals or by replacing the marrow spaces directly by cortical bone resorption.9,10 In the current study, bone invasion was found among $38 \%$ of the total patients studied. Bone invasion was identified as a prognostic factor in cervical metastases in the study conducted by Ogura et al. 11

Muscle invasion occurs by the infiltration of extrinsic skeletal muscle bundles by malignant cells. ${ }^{12}$ Studies exclusively on muscle invasion are rarely done, rendering its clinical relevance and its prognosis unknown. Therefore, its exact prognostic value or outcome has not been assessed. A study done by Min et al. has described that muscle invasion by a squamous cell carcinoma involving posterior mandibular alveolar ridge was associated with a cervical nodal metastasis. ${ }^{13} 33 \%$ of the patients showed histopathologic evidence of muscle invasion in our study suggesting that along with other established prognosticators, muscle invasion could be the reliable prognostic factor for determining the prognosis of the patient. Chandler k et al. hypothesized that the muscle invasion as a surrogate prognostic factor for depth of invasion can be correlated similarly for occult lymph node metastasis. ${ }^{14}$

In squamous cell carcinoma of head and neck the prognostic significance of perineural invasion has been investigated thoroughly. Perineural invasion was found to be positively correlated with lymph node status and recurrences. ${ }^{15,16}$ But few studies reported no difference in outcome when perineural invasion was histopathologically evident. 17,18 In the present study, perineural invasion was seen in only $15 \%$ of the total patients. Some studies aimed to determine the prognostic value of extracapsular spread through comparison of macroscopic and microscopic extracapsular spread.19,20 These studies proposed that extracapsular spread had prognostic significance when it was macroscopically recognized, whereas microscopic extracapsular spread was rejected as a significant prognosticator in these studies. Several other studies found no difference in prognosis of the patients when compared between microscopic and macroscopic extracapsular spread.21,22,23,24 In the current study, $38 \%$ of patients had histopathological evidence of extracapsular spread.

Among the above mentioned clinicopathological parameters, habits $(\mathrm{P}=0.043)$, tumour differentiation $(\mathrm{P}=$ 0.004), tumour size $(\mathrm{P}=0.041)$, perineural invasion $(\mathrm{P}=$ $0.043)$ and extracapsular spread $(P=0.000)$ were significantly correlated with lymph node status of the patients by using chi square test. To check the independency of the prognosticators we conducted multivariate logistic regression analysis which concluded that prognostic factors such as habits (P value0.045 ), clinical tumour size ( $P$ value -0.003 ) and perineural invasion (P value - 0.000 ) were independent prognosticators.

For Indian population, both chewable and smoke form of tobacco act synergistically in oral carcinogenesis in those individuals with mixed habits which eventually form a high risk population. ${ }^{25,26}$ All the patients in our study had a history of tobacco consumption (predominantly smokeless). The various epidemiological studies conducted by various authors reported use of smokeless tobacco as an important causative factor of oral cancer particularly in india and the risk of developing oral carcinomas in chewers (combinations of areca nut, betel leaf, tobacco and lime) was 2 - 4 times higher as compared to those individuals with no tobacco habits. ${ }^{26,27,28}$ In a retrospective study conducted by Shenoi et al. ${ }^{29}$ Gingivobuccal sulcus is the commonly involved site in tobacco chewers because of the placement of the tobacco quid which acts as a contact carcinogen. Other patients had tobacco habits asscociated with alcohol consumption. Alcohol alone is not a risk factor for oral carcinomas but tobacco in combination with alcohol have synergistic effect for carcinogenesis. As nicotine promotes lymph node metastasis, individuals with existing malignant lesion with habit continuation will directly affect the cancer progression, metastasis and prognosis. Habit has been recognised as an independent prognosticator in our study and is significantly correlated to the lymph node status.

$38.33 \%$ of patients in our study had metastatic lymph nodes out of which majority had clinical tumour size of $2-4$ cm (T2). A radiology based study conducted by khan SA et al. showed a strong positive significant correlation in between the tumor size (more than $4 \mathrm{~mm}$ transversely) and lymph node metastasis. ${ }^{30}$ Madana J et al. compared the radiological (CT) measurements of tumor thickness with histopathology and found them closely related to each other. ${ }^{31}$ Clinical tumour size has been significantly correlated with lymph node status in our study and recognised as an independent prognostic factor. Similar observations were noted in the retrospective study conducted by Alessandro Menna Alves. ${ }^{32}$

Perineural invasion is usually defined as a microscopic identification of small unnamed peripheral nerves within the vicinity of an invasive tumor. ${ }^{33}$ It is a well-recognized factor associated with poor prognosis. A study conducted by $\mathrm{G}$ Deepthi et al. $63.6 \%$ and $50 \%$ showed positivity for perineural invasion in T3 and T4 tumour stages with high significance. $^{34}$ Whereas in our study only $15 \%$ cases showed perineural positivity and all of them were in T2 tumour stage. It was significantly correlated with the lymph node status in our study and was recognised as an independent prognosticator.

\section{CONCLUSIONS}

This analysis suggests that habit, tumour size and perineural invasion to be consistent, easy to assess, and reliable independent prognosticators that are significantly correlated to the lymph node status. To conclude, it is of paramount importance to include the aforementioned prognosticators in histopathological reports for the prediction of clinical outcome and archiving of valued data for future analysis.

Data sharing statement provided by the authors is available with the full text of this article at jemds.com.

Financial or other competing interests: None.

Disclosure forms provided by the authors are available with the full text of this article at jemds.com.

Authors would like to thank the Department of Oral \& Maxillofacial Pathology and Department of Oral \& Maxillofacial Surgery for their cooperation. 


\section{REFERENCES}

[1] Pires FR, Ramos AB, Oliveira JB, et al. Oral squamous cell carcinoma: clinicopathological features from 346 cases from a single oral pathology service during an 8-year period. J Appl Oral Sci 2013;21(5):460-7.

[2] Mandlik DS, Nair SS, Patel KD, et al. Squamous cell carcinoma of gingivobuccal complex: literature, evidences and practice. J Head Neck Physicians Surg 2018;6(1):1828.

[3] Acharya S, Sivakumar AT, Shetty S. Cervical lymph node metastasis in oral squamous cell carcinoma: a correlative study between histopathological malignancy grading and lymph node metastasis. Indian J Dent Res 2013;24(5):599-604.

[4] Walvekar RR, Chaukar DA, Deshpande MS, et al. Squamous cell carcinoma of the gingivobucca complex: predictors of locoregional failure in stage III-IV cancers. Oral Oncol 2009;45(2):135-40.

[5] Pathak KA, Gupta S, Talole S, et al. Advanced squamous cell carcinoma of lower gingivobucca complex: patterns of spread and failure. Head Neck 2005;27(7):597-602.

[6] Fang KH, Kao HK, Cheng MH, et al. Histological differentiation of primary oral squamous cell carcinomas in an area of betel quid chewing prevalence. Otolaryngol Head Neck Surg 2009;141(6):743-9.

[7] Rikardsen OG, Bjerkli IH, Uhlin-Hansen L, et al. Clinicopathological characteristics of oral squamous cell carcinoma in Northern Norway: a retrospective study. BMC Oral Health 2014;14:103.

[8] Choi PW, Yu CS, Jang SJ, et al. Risk factors for lymph node metastasis in submucosal invasive colorectal cancer. World J Surg 2008;32(9):2089-94.

[9] Totsuka Y, Amemiya A, Tomita K. Histopathologic study of bone invasion by DMBA-induced carcinoma of the mouth in the hamster. Oral Surg Oral Med Oral Pathol 1986;62(6):683-92.

[10] Totsuka Y, Usui Y, Tei K, et al. Mandibular involvement of squamous cell carcinoma of the lower alveolus: analysis and comparative study of histologic and radiologic features. Head Neck 1991;13(1):40-50.

[11] Ogura I, Kurabayashi T, Amagasa T, et al. Mandibular bone invasion by gingival carcinoma on dental CT images as an indicator of cervical lymph node metastasis. Dentomaxillofac Radiol 2002;31(6):339-43.

[12] Mani C, Lakshminarayana G, Kurian A, et al. Predictors of recurrence in early stage oral tongue squamous cell carcinoma. J Orofac Sci 2015;7(2):86-9.

[13] Min SK, Myoung H, Lee JH, et al. Muscular invasion by oral squamous cell carcinoma of the posterior mandibular alveolar ridge is associated with cervical lymph node metastasis. J Korean Assoc Oral Maxillofac Surg 2016;42(3):133-8.

[14] Chandler K, Vance C, Budnick S, et al. Muscle invasion in oral tongue squamous cell carcinoma as a predictor of nodal status and local recurrence: just as effective as depth of invasion? Head Neck Pathol 2011;5(4):359-63.

[15] Tai SK, Li WY, Yang MH, et al. Treatment for T1-2 oral squamous cell carcinoma with or without perineural invasion: neck dissection and postoperative adjuvant therapy. Ann Surg Oncol 2012;19(6):1995-2002.
[16] Chatzistefanou I, Lubek J, Markou K, et al. The role of neck dissection and postoperative adjuvant radiotherapy in cNo patients with PNI-positive squamous cell carcinoma of the oral cavity. Oral Oncol 2014;50(8):753-8.

[17] Liao CT, Chang JT, Wang HM, et al. Does adjuvant radiation therapy improve outcomes in pT1-3N0 oral cavity cancer with tumor-free margins and perineural invasion? Int J Radiat Oncol Biol Phys 2008;71(2):371-6.

[18] Chen TC, Wang CP, Ko JY, et al. The impact of perineural invasion and/or lymphovascular invasion on the survival of early-stage oral squamous cell carcinoma patients. Ann Surg Oncol 2013;20(7):2388-95.

[19] Ferlito A, Rinaldo A, Devaney KO, et al. Prognostic significance of microscopic and macroscopic extracapsular spread from metastatic tumor in the cervical lymph nodes. Oral Oncol 2002;38(8):747-51.

[20] De Carvalho MB. Quantitative analysis of the extent of extracapsular invasion and its prognostic significance: a prospective study of 170 cases of carcinoma of the larynx and hypopharynx. Head Neck 1998;20(1):16-21.

[21] Shaw RJ, Lowe D, Woolgar JA, et al. Extracapsular spread in oral squamous cell carcinoma. Head Neck 2010;32(6):714-22.

[22] Woolgar JA, Rogers SN, Lowe D, et al. Cervical lymph node metastasis in oral cancer: the importance of even microscopic extracapsular spread. Oral Oncol 2003;39(2):130-7.

[23] Greenberg JS, Fowler R, Gomez J, et al. Extent of extracapsular spread: a critical prognosticator in oral tongue cancer. Cancer 2003;97(6):1464-70.

[24] Oztürk C, Saraydarğolu O, Erişen L, et al. The relationship between lymph node size and metastasis and extracapsular spread in squamous cell carcinoma of the larynx, orohypopharynx and oral cavity. Kulak Burun Bogaz Ihtis Derg 2008;18(1):7-13.

[25] Jayant K, Balakrishnan V, Sanghvi LD, et al. Quantification of the role of smoking and chewing tobacco in oral, pharyngeal and oesophageal cancers. $\mathrm{Br} \mathrm{J}$ Cancer 1977;35(2):232-5.

[26] Jussawalla DJ, Deshpande VN. Evaluation of cancer risk in tobacco chewers and smokers: an epidemiologic assessment. Cancer 1971;28(1):244-52.

[27] Nandakumar A, Thimmasetty KT, Sreeramareddy NM, et al. A population-based case-control investigation on cancers of the oral cavity in Bangalore, India. Br J Cancer 1990;62(5):847-51.

[28] Sankaranarayanan R, Duffy SW, Padmakumary G, et al. Risk factors for cancer of the buccal and labial mucosa in Kerala, Southern India. J Epidemiol Community Health 1990;44(4):286-92.

[29] Shenoi R, Devrukhkar V, Sharma BK, et al. Demographic and clinical profile of oral squamous cell carcinoma patients: a retrospective study. Indian J Cancer 2012;49(1):21-6.

[30] Khan SA, Zia S, Naqvi SU, et al. Relationship of oral tumor thickness with the rate of lymph node metastasis in neck based on CT scan. Pak J Med Sci 2017;33(2):353-7.

[31] Madana J, Laliberté F, Morand GB, et al. Computerized tomography based tumor-thickness measurement is useful to predict postoperative pathological tumor thickness in oral tongue squamous cell carcinoma. J Otolaryngol Head Neck Surg 2015;44:49. 
[32] Alves AM, Correa MB, Da Silva KD, et al. Demographic and clinical profile of oral squamous cell carcinoma from a service-based population. Brazilian Dental Journal 2017;28(3):301-6.

[33] Brown IS. Pathology of perineural spread. J Neurol Surg B Skull Base 2016;77(2):124-30.
[34] Deepthi G, Shyam NDVN, Kumar GK, et al. Characterization of perineural invasion in different histological grades and variants of oral squamous cell carcinoma. J Oral Maxillofac Pathol 2020;24(1):57-63. 